\title{
ANÁLISE dA FLEXÃO VERBAL DE TEMPO NA ESCRITA DE SURDOS SINALIZADORES
}

\author{
ANALYSIS OF VERBAL INFLECTION IN THE WRITTEN \\ PRODUCTION OF DEAF SIGNERS
}

\author{
Aline Nascimento CRATO ${ }^{1}$ \\ Maria Silvia CÁRNIO²
}

\begin{abstract}
RESUM O: a produção escrita de estudantes surdos tem sido objeto de estudos nacionais e internacionais devido às histórias recorrentes de fracassos escolares e as dificuldades de ensino por parte dos educadores em propiciar a significação da Língua Escrita para esta população especifica. Pesquisas nacionais enfatizam que os surdos apresentam dificuldades na escrita do português, principalmente no uso de verbos. Buscando compreender melhor este processo, o presente estudo teve por objetivo avaliar a flexão verbal de tempo na escrita de surdos sinalizadores e observar a presença de outros marcadores de tempo em suas frases. 0 estudo foi realizado com vinte e dois sujeitos, com idade entre 14 e 24 anos e escolaridade de 3a a 7a série do Ensino Fundamental. Estes indivíduos foram avaliados quanto ao conhecimento em Língua Brasileira de Sinais de seis verbos de ação (por meio de cartelas contendo figuras representando estas ações) e em seguida foram orientados a escrever três frases com cada verbo, sendo uma no tempo passado, uma no presente e uma no futuro. Os dados foram avaliados qualitativa e quantitativamente e demonstraram que os sujeitos apresentaram dificuldade na flexão verbal de tempo, havendo o predomínio do verbo na forma nominal do infinitivo. Quanto a outros marcadores de tempo utilizados nas frases, os advérbios de tempo foram os mais freqüentes. Os sujeitos que estavam matriculados em séries mais avançadas apresentaram melhor uso das flexões verbais de tempo e fizeram uso mais freqüente de outros marcadores de tempo. Conclui-se que apesar de um longo tempo de escolaridade, a maioria dos surdos do estudo não sabe realizar a flexão verbal de tempo da Língua Portuguesa. Este fato demonstra a necessidade de repensar as práticas de ensino da Língua Portuguesa, como segunda língua, para que os surdos tenham a oportunidade de apropriar-se cada vez mais cedo da escrita, e participar ativamente da sociedade.
\end{abstract}

PALAVRAS-CHAVE: Surdez. Linguagem escrita. Língua brasileira de sinais. Educação Especial.

ABSTRACT: written production of deaf students has been the focus of national and international studies due to recurrent cases of academic failure and to the problems teachers encounter as they attempt to ensure understanding of the written language for this specific population. N ational research emphasizes that deaf students present difficulties in writing in Portuguese, specifically in verb use. In order to better understand this process, this study aimed to assess verbal inflection for tense in deaf signers' written production and to observe the presence of other tense markers in their sentences. The study was carried out with twenty two subjects, ranging in age from 14 to 24 years, with an educational level varying from the $3^{\text {rd }}$ to the $7^{\text {th }}$ grade Elementary School level. Subjects were assessed concerning their knowledge of six action verbs in Brazilian Sign Language (using boards with pictures representing the actions) and then they were asked to write three sentences with each verb, one in the past tense, one in the present and one in the future tense. Analysis of

\footnotetext{
${ }^{1}$ Fonoaudióloga formada pela Universidade Federal de Minas Gerais, com Especialização em Fonoaudiologia e Mestranda do programa de pós-graduação em Ciências da Reabilitação - Comunicação Humana do Departamento de Fisioterapia, Fonoaudiologia e Terapia Ocupacional da Faculdade de Medicina da Universidade de São Paulo. aline.crato@bol.com.br Vinculo institucional: Universidade de São Paulo.

${ }^{2}$ Doutora em Semiótica e Lingüística Geral pela Faculdade de Filosofia, Letras e Ciências Humanas da Universidade de São Paulo (FFLCH- USP). Docente do Curso de Fonoaudiologia do Departamento de Fisioterapia, Fonoaudiologia e Terapia Ocupacional da Faculdade de Medicina da Universidade de São Paulo. mscarnio@usp.br Vinculo institucional: Universidade de São Paulo.
} 
data was carried out in terms of qualitative and quantitative results. The results showed that subjects presented difficulty in tense inflection, using predominantly the verb in the nominal form of the infinitive. Adverbs of time were the most frequent tense markers used in the sentences. Subjects enrolled in the most advanced grades presented better use of tense inflection and used other tense markers more frequently. The conclusion was that despite many years of schooling, most deaf students do not know how to use verbal inflection for tense in Portuguese. This fact demonstrates the need for rethinking practices of Portuguese teaching as a second language in order that deaf students may have the opportunity to master writing earlier, which will help them to participate more actively in society.

KEYWORDS: Deafness. Written language. Brazilian sign Ianguage. Special Education.

\section{INTRODUÇão}

A produção escrita de surdos vem sendo amplamente estudada (CÁRNIO， 1986; MIDENA,1989; FERNANDES, 1990; CÁRNIO, 1995; QUADROS, 1997; SOUZA, 1998; FERREIRA; CÁRNIO, 1999; LODI, HARRISON ; CAMPOS, 2002; PEREIRA, 2002; FERN ANDES, 2003; GESUELI, 2006;) devido à grande dificuldade destes indivíduos no aprendizado da leitura e escrita. É comum a permanência de surdos em séries iniciais sem uma produção escrita condizente com sua escolaridade, mesmo após anos de estudo.

De acordo com Quadros (1997), Caporali, Lacerda e Marques (2005) e Pereira (SÃO PAULO, 2005), um dos grandes obstáculos no aprendizado da leitura e da escrita pelas crianças surdas resulta na ausência de uma base lingüística consolidada. Isto se deve ao fato da maioria ter nascido em lares de pais ouvintes, que usam o português oral e que desconhecem a língua de sinais, sendo que o acesso à língua oral, na melhor das hipóteses, ocorre de forma fragmentada.

Com base nestas constatações, al gumas reflexões são importantes para se discutir as condições educacionais e familiares desta população específica, uma vez que deacordo com as pesquisas, as dificuldades enfrentadas pelos surdos parecem ser conseqüências destas duas condições.

Para otimizar a falta de uma língua estruturada dos estudantes surdos quando entram na escola, os professores oferecerem frases prontas que atendem aos requisitos morfossintáticos da Língua Portuguesa (MIDEN A, 1989; FERREIRA; CÁRNIO, 1999; GÓES, 1999; BOTELHO, 2002). Este tipo de método de ensino se mostrou ineficiente, pois apesar de algumas crianças utilizarem estruturas frasais gramaticalmente corretas, era observada a presença de frases estereotipadas, sem criatividade e muitas vezes sem sentido (SÃO PAULO, 2005).

Se as crianças surdas tivessem acesso à língua de sinais precocemente poderia se garantir o desenvolvimento da linguagem e favorecer o aprendizado da Língua Portuguesa escrita, como segunda língua, de forma mais rápida e significativa (QUADROS, 1997; PEREIRA, 2002). Esta afirmação corrobora a literatura internacional que menciona a relação significante da competência 
lingüística da língua de sinais como suporte para as habilidades de escrita de crianças surdas (STRONG; PRINZ, 1997; WILLIAMS, 1999, RATHMAN N, MANN; MORGAN, 2007).

O acesso a língua de sinais pela criança surda deveria ser realizado em um ambiente favorável. Para que isso ocorra é importante que pais e professores de surdos tenham motivação e passem a utilizar a língua de sinais rotineiramente. Quando o professor não compartilha uma mesma língua com o estudante surdo ou quando o estudante não tem uma língua de sinais ou oral estabelecida, o professor ficará impossibilitado de realizar um trabalho satisfatório (KYLE, 2001a).

De acordo com a literatura internacional o currículo educacional de uma proposta bilíngüe deve abordar a cultura surda e a língua de sinais, transmitidos por um surdo (PICKERSGILL; GREGORY, 1998).

Kyle (2001b) relata que assim como as crianças ouvintes do Brasil estudam o Português nas escolas, as crianças surdas também deveriam ter um programa curricular extenso para o estudo da Língua Brasileira deSinais (Libras) em todos os níveis da educação.

O estudo da língua de sinais favoreceria a consciência metalingüística dos surdos (RATHMANN, MANN; MORGAN, 2007) e contribuiria para a conscientização das diferenças normativas da Libras e da Língua Portuguesa escrita quando fosse realizado um trabalho pedagógico sistemático e eficiente (GESUELI, 2006; PEIXOTO, 2006).

$\mathrm{Na}$ pesquisa realizada por Cárnio et al. (2000) foi constatado que quando existe uma base lingüística bem definida, seja na língua de sinais ou na língua oral, maior é a motivação na realização de atividades de leitura e escrita. Lodi (2004) encontrou resultados similares no seu estudo com surdos adultos e enfatizou que a Libras foi um fator importante para uma leitura compreensiva e dialógica dos sujeitos.

\section{EdUCAÇÃO dOS SURDOS}

A pesar das discussões em todo o território nacional sobre a inclusão dos surdos em escolas regulares, este é um tema que preocupa sobremaneira os professores, que se consideram despreparados para receber estes estudantes. De acordo com Góes e Tartuci (2002) as políticas sociais e lingüísticas que afetam as minorias, as diretrizes da educação e as orientações para a educação do surdo são por vezes divergentes em relação à condição bilíngüe destes indivíduos.

A Dedaração de Salamanca (UNESCO, 1994) gera ambigüidades, pois recomenda a inclusão de todos os portadores de necessidades educativas especiais em classes regulares, e, ao mesmo tempo referencia a importância da língua de sinais na educação dos surdos, esclarecendo que, devido às especificidades decomunicação destes indivíduos, seria mais adequada que sua educação fosse oferecida em escolas especiais ou em classes especiais nas escolas regulares. 
Infelizmente, apesar das escolas especiais para surdos do Brasil utilizar a Libras como forma de comunicação, observa-se que a maioria dos professores tem pouco conhecimento a respeito da surdez e da língua de sinais, e o estudo da estrutura desta língua não faz parte do programa curricular.

Deste modo, a Libras torna-se subordinada à estrutura sintática da Língua Portuguesa, que é ensinada com ênfase no vocabulário e memorização de regras gramaticais, ignorando o conhecimento lingüístico e de mundo dos surdos (KARN OPP, 2002).

As dificuldades de aquisição da Língua Portuguesa não podem ser atribuídas apenas às práticas pedagógicas realizadas, mas ao pouco conhecimento que os surdos apresentam desta língua quando chegam à escola (KARNOPP; PEREIRA, 2004). Para que a escola cumpra o seu papel, não basta que o surdo apenas compreenda e se relacione com a escrita, mas que Ihe sejam proporcionadas situações nas quais possam refletir sobre o que lêem e escrevem (GON ÇALO, 2004).

De acordo com os Parâmetros Curriculares Nacionais (BRASIL, 1999), devem ser realizadas adaptações ao currículo regular, considerando-se as peculiaridades dos alunos com necessidades educativas especiais.

Para a inclusão dos surdos na escola regular além da adequação curricular devem ser realizadas algumas medidas para o adequado atendimento destes estudantes, que indui mudanças didáticas e metodológicas, conhecimento dos professores sobrea surdez ea língua desinais, além da presença deum intérprete, para que seja respeitada a situação bilíngüe dos surdos (LACERDA, 2006).

\section{O USO dos VERBos NA ESCRITA Do PORTUGUÊS dE SUJEITOS SURDOS E A MARCAÇão DE TEM PO NA LIBRAS}

No Brasil existe escassez de estudos que fornecem informações sobre o uso deverbos na produção escrita desurdos. Góes (1999) observou o predomínio do uso de nomes, muitas vezes usados no lugar de verbos, a ocorrência de terminações verbais não correspondentes à pessoa verbal, inconsistência do tempo e modo verbal caracterizada, principalmente, pela alternância inadequada do tempo presente e passado e termi nações incorretas para tempo e pessoa do verbo.

Embora o verbo possa apresentar-se lexicalmente correto na escrita dos surdos, não há domínio dos tempos e pessoas no processo da construção frasal (FERNANDES, 2003). Além disso, é comum a presença de verbos sem flexões ou ausentes (SÃO PAULO, 2005).

Na produção escrita de surdos que cursavam o último ano do Ensino Médio ou que já tinham concluído este nível escolar, Gonçalo (2004) observou bom uso do tempo verbal, apesar da dificuldade expressiva dos sujeitos na flexão verbal de pessoa. 
De acordo com as pesquisas realizadas, os surdos apresentam dificuldade no uso do verbo na escrita do português. Esta afirmação é inquestionável, contudo a origem desta dificuldade ainda é polêmica, sendo atribuída a vários fatores, tais como: influência da Libras, dificuldade de acesso à Língua Portuguesa e práticas de ensino descontextualizadas.

$\mathrm{Na}$ Libras, o momento da ação não está codificado por meio de processos flexionais no verbo. Existem marcadores de tempo não verbais e recursos para indicar a progressão ou repetição do acontecimento (SALLES et al, 2004). O tempo do discurso pode ser evidenciado pela indicação do sinal "ANO PASSADO" ou por meio de um item lexical que indica este tempo, por exemplo, em "ONTEM" $\mathrm{e}$ "ANTEONTEM". O presente pode ser configurado pelo sinal de "HOJE" e "AGORA". O futuro pode ser indicado pelo sinal de "AMANHÃ" e “DAQUI A MUITO TEMPO" (FERREIRA-BRITO, 1995).

Segundo Felipe (2005), na Libras, a indicação de tempo está representada por advérbios de tempo. Quando a frase não tiver um advérbio de tempo específico, pode-se utilizar o sinal "PASSADO" para frases no tempo passado e o sinal de "FUTURO" para frases no futuro. As frases no presente geralmente não apresentam nenhuma especificação temporal.

Com base no exposto anteriormente, a presentepesquisa teve o objetivo deanal isar a utilização da flexão verbal de tempo na escrita desurdos sinalizadores e observar a presença de outros marcadores de tempo em suas frases.

\section{MÉTodo}

Este estudo foi aprovado pela Comissão de Ética para Análise de Projetos de Pesquisa (CAPPesq) da Diretoria Clínica do Hospital das Clínicas e da Faculdade de Medicina da Universidade de São Paulo, sob protocolo número 1277/ 06, conforme resolução 196/ 96 da Comissão Nacional de Ética e Pesquisa (CONEP). Optou-se pela realização de uma pesquisa avaliativa e mista (com tratamento dos dados de forma qual itativa e quantitativa) com a finalidade de se obter um conjunto de dados complementares que possibilitem a discussão de aspectos específicos da produção escrita dos surdos, os quais na prática parecem evidentes, contudo na teoria nem sempre são explorados.

\section{Sujeitos}

Participaram da pesquisa 22 sujeitos surdos, sendo doze do sexo masculino e dez do feminino, atendidos em uma instituição do interior de São Paulo.

Os critérios de inclusão dos sujeitos foram: diagnóstico de perda auditiva neurossensorial severa a profunda bilateral prélingüístico; filhos de pais ouvintes; idade variando de 14 a 24 anos; matriculados em escolas públicas, em sala regular, freqüentando desde a $3^{a}$ até a $7 \underline{a}$ série do Ensino fundamental; que utilizassem a Libras como meio predominante de comunicação, sem a presença 
de intérpretes; e sem comprometimentos associados. É importante esclarecer que todos os sujeitos freqüentaram escola especial por quatro anos ou mais.

\section{Materiais e procedimentos}

Os sujeitos ou responsáveis foram convocados a comparecer na instituição para serem esclarecidos e convidados a participar da referida pesquisa, assinando, para tanto, um termo de consentimento livre e esclarecido.

A pós a assinatura do termo de consentimento todos os sujeitos passaram por avaliação fonoaudiológica da escrita e responderam um questionário sobre a trajetória lingüística e escolar.

Para a avaliação da escrita foram utilizadas seis cartelas contendo desenhos com imagens lúdicas e expressivas de verbos regulares e dissílabos retirados do "Caderno Ilustrado de Verbos: um recurso pedagógico para o desenvolvimento da Língua Portuguesa", elaborado por Quintano-N eira eCárnio (2005).

Para a sel eção dos verbos, procurou-seevitar aqueles nos quais o sinal correspondente na Libras fosse igual ou semel hante ao substantivo, como por exemplo, o sinal de "DIRIGIR" e "CARRO". Desta forma, as cartelas escolhidas para a avaliação foram dos verbos: comer, correr, jogar, pular, limpar, e pegar.

Inicialmente foram apresentadas aos pacientes as cartelas contendo as imagens de ações referentes aos verbos e sol icitada que fosse real izado o sinal correspondente a cada verbo, em Libras, para que fosse garantido o real entendimento dos verbos mostrados nas cartelas.

A pós esta atividade, os pacientes foram instruídos a escreverem o nome do verbo apresentado na cartela, e elaborarem três frases escritas contendo o referido verbo, sendo uma no tempo passado, uma no presentee uma no futuro. N esteestudo, não foram analisados a flexão verbal relacionada ao número, pessoa, modo e voz do verbo.

Durante toda a avaliação a pesquisadora executante utilizou a Libras para se comunicar com os sujeitos.

As avaliações foram filmadas em uma sala apropriada para posterior análise das flexões verbais de tempo, nas quais foram utilizados os critérios da Gramática da Língua Portuguesa (CEGALLA, 2001).

Os dados relativos ao tempo que os sujeitos freqüentaram a escola regular e especial, série escolar, flexão verbal de tempo e outros marcadores de tempo das frases, passaram por tratamento estatístico. Para comparar se houve diferença estatisticamente significante entre o tempo de permanência dos sujeitos na escola regular e na especial foi utilizado o teste ANOVA e para comparar a série escolar com a flexão verbal de tempo e os outros marcadores de tempo 
das frases foi utilizado o teste Qui-Quadrado para Independência. Por questão de quantidade amostral foi realizado um agrupamento das $3^{\text {as }}$ e $4^{\text {as }}$ séries e das $5 \stackrel{a}{a}, 6^{\mathfrak{a} s}$ e $7^{\mathfrak{a} s}$, a fim de se obter uma melhor análise estatística.

O nível de significância adotado foi de 0,05 (5\%), e todos os intervalos de confiança construídos ao longo do trabalho foram feitos com 95\% de confiança estatística.

\section{RESULtAdos e discussão}

Os resultados encontrados corroboram a literatura (QUADROS, 1997) quando observa-se a presença de surdos em séries iniciais, mesmo quando apresentam um tempo de escolaridade elevado (tabela 1).

A variação no tempo de escolaridade de nove a dezessete anos, pode ser explicada pelos relatos de repetência de todos os sujeitos, registrados nas anamneses. Segundo Botelho (2002), a lentidão do processo de escolarização do surdo é fruto de um ritmo imposto pelo professor. Esta é uma das queixas feitas pelos surdos na pesquisa realizada por Gonçalo (2004), os quais referem um tratamento diferenciado dos professores de escolas especiais no sentido de que cada série seja cumprida em dois anos letivos.

Tabela 1 - Caracterização dos sujeitos.

\begin{tabular}{c|c|c|c|c|c|c}
\hline \multirow{2}{*}{ Sujeitos } & \multirow{2}{*}{ Sexo } & \multirow{2}{*}{ Idade } & \multirow{2}{*}{ Série } & \multicolumn{2}{|c|}{ Tempo de permanência } & \multirow{2}{*}{$\begin{array}{c}\text { Tempo de } \\
\text { Escolaridade }\end{array}$} \\
\cline { 5 - 6 } & & & & Escola Especial & Escolar Regular & 9 anos \\
2 & $\mathrm{M}$ & 14 anos & $3^{\mathrm{a}} \mathrm{EF}$ & 8 & 3 & 11 anos \\
2 & $\mathrm{~F}$ & 15 anos & $3^{\mathrm{a}} \mathrm{EF}$ & 8 & 1 & 12 anos \\
3 & $\mathrm{M}$ & 18 anos & $3^{\mathrm{a}} \mathrm{EF}$ & 11 & 6 & 13 anos \\
4 & $\mathrm{M}$ & 19 anos & $3^{\mathrm{a}} \mathrm{EF}$ & 7 & 4 & 10 anos \\
5 & $\mathrm{M}$ & 14 anos & $4^{\mathrm{a}} \mathrm{EF}$ & 6 & 4 & 10 anos \\
6 & $\mathrm{M}$ & 14 anos & $4^{\mathrm{a}} \mathrm{EF}$ & 6 & 3 & 12 anos \\
7 & $\mathrm{M}$ & 17 anos & $4^{\mathrm{a}} \mathrm{EF}$ & 9 & 3 & 13 anos \\
8 & $\mathrm{~F}$ & 18 anos & $4^{\mathrm{a}} \mathrm{EF}$ & 10 & 2 & 13 anos \\
9 & $\mathrm{~F}$ & 18 anos & $4^{\mathrm{a}} \mathrm{EF}$ & 11 & 1 & 15 anos \\
10 & $\mathrm{M}$ & 23 anos & $4^{\mathrm{a}} \mathrm{EF}$ & 14 & 1 & 10 anos \\
11 & $\mathrm{M}$ & 16 anos & $5^{\mathrm{a}} \mathrm{EF}$ & 9 & 8 & 12 anos \\
12 & $\mathrm{~F}$ & 16 anos & $5^{\mathrm{a}} \mathrm{EF}$ & 4 & 3 & 10 anos \\
13 & $\mathrm{M}$ & 19 anos & $5^{\mathrm{a}} \mathrm{EF}$ & 7 & 5 & 13 anos \\
14 & $\mathrm{M}$ & 19 anos & $5^{\mathrm{a}} \mathrm{EF}$ & 8 & 2 & 15 anos \\
15 & $\mathrm{~F}$ & 20 anos & $5^{\mathrm{a}} \mathrm{EF}$ & 13 & 2 & 14 anos \\
16 & $\mathrm{M}$ & 22 anos & $5^{\mathrm{a}} \mathrm{EF}$ & 12 & 2 & 14 anos \\
17 & $\mathrm{~F}$ & 20 anos & $6^{\mathrm{a}} \mathrm{EF}$ & 12 & 3 & 14 anos \\
18 & $\mathrm{~F}$ & 21 anos & $6^{\mathrm{a}} \mathrm{EF}$ & 11 & 2 & 12 anos \\
19 & $\mathrm{~F}$ & 24 anos & $6^{\mathrm{a}} \mathrm{EF}$ & 15 & 8 & 12 anos \\
20 & $\mathrm{~F}$ & 15 anos & $7^{\mathrm{a}} \mathrm{EF}$ & 4 & 7 & 14 anos \\
21 & $\mathrm{M}$ & 16 anos & $7^{\mathrm{a}} \mathrm{EF}$ & 5 & 10 & \\
22 & $\mathrm{~F}$ & 18 anos & $7^{\mathrm{a}} \mathrm{EF}$ & 4 & &
\end{tabular}

Legenda:

$M$ : masculino - F: feminino

EF: Ensino Fundamental 
A Tabela 2 ilustra a comparação do tempo de permanência dos sujeitos na escola regular e especial, por meio do teste ANOVA. Observa-se que existe diferença média estatisticamente significante entre o tempo de permanência na escola regular $(3,68 \pm 1,08)$ e especial $(8,82 \pm 1,37)$. 0 fato dos surdos freqüentarem por um período maior a escola especial se deve, segundo relato dos mesmos, à resistência das escolas regulares em aceitar suas matrículas, por não serem fluentes na língua oral . N ota-se por estes rel atos, o desconhecimento por partes das famílias destes surdos, sobre a Declaração de Salamanca, feita em 1994 (UNESCO, 1994), a qual já garantia o direito de todos os indivíduos com necessidades educativas especiais de estarem matriculados no ensino regular. Entretanto, o que se tem observado é que com este direito adquirido os surdos estão sendo inseridos na escola regular sem uma inclusão real. Nota-se na maioria das escolas a falta de medidas para o adequado ensino desta população, queinclui adaptações di dáticas e metodológicas, preparação dos professores e a presença de um intérprete de Libras (LACERDA, 2006).

Tabela 2 - Comparação entre o tempo de permanência dos sujeitos em escola regular e especial.

\begin{tabular}{c|c|c}
\hline Escola & Regular & Especial \\
\hline Média & 3,68 & 8,82 \\
Mediana & 3 & 8,5 \\
Desvio Padrão & 2,59 & 3,29 \\
CV & $70,3 \%$ & $37,3 \%$ \\
Q1 & 2 & 6,25 \\
Q3 & 4,75 & 11 \\
Mínimo & 1 & 4 \\
Máximo & 10 & 15 \\
N & 22 & 22 \\
IC & 1,08 & 1,37 \\
\hline p-valor & \multicolumn{2}{|l|}{$<0,001^{*}$} \\
\hline
\end{tabular}

Legenda:

CV: Coeficiente de Variação - IC: Intervalo de Confiança

$\mathrm{N}$ : Número de sujeitos - *: p-valores considerados estatisticamente significantes

Q1: 1 quartil mostra a distribuição até $25 \%$ da amostra

Q3: 3o quartil mostra a distribuição até 75\% da amostra

As campanhas real izadas em todo o âmbito nacional sobre a inclusão das pessoas com necessi dad es educativas especiais no ensino regular contribuíram para que os surdos da pesquisa fossem inseridos em escolas regulares há pelo menos um ano.

Segundo Samelli et al (2002), para a colocação dos surdos nas classes especiais deveriam ser considerados o nível de escolaridade, o desenvolvimento lingüístico e a faixa etária dos indivíduos. 
$\mathrm{Na}$ inclusão tardia de surdos em classes regulares, a proposta apresentada pelos autores torna-se impossível, pois se for considerada a faixa etária, o surdo será incluído em séries nas quais não irá conseguir acompanhar os alunos ouvintes; e, se forem observados o nível de escolaridade e o desenvolvimento lingüístico, o surdo será incluso em salas com crianças mais novas, o que pode causar desconforto para o mesmo e dificuldade de aceitação deste por parte dos ouvintes.

Nenhuma das escolas freqüentadas pelos sujeitos conta com a pre sença de um intérprete de Libras em sala de aula. Este fato é preocupante, uma vez que segundo Lacerda (2000), na ausência de um intérprete, o professor tendea simplificar os conteúdos ediminuir sua exigência, com o intuito de minimizar as dificuldades relativas à comunicação com os estudantes surdos.

Quanto ao desempenho dos sujeitos no uso da flexão verbal de tempo das frases escritas, observa-se que dos 22 sujeitos, três flexionaram os verbos adequadamente nos três tempos solicitados e quatro realizaram a flexão do verbo apenas no tempo presente (tabela 3).

Tabela 3 - Flexões verbais de tempo e outros marcadores de tempo das frases dos sujeitos discriminados no passado, presente e futuro.

\begin{tabular}{|c|c|c|c|c|c|c|}
\hline \multirow[b]{2}{*}{ Sujeitos } & \multicolumn{2}{|c|}{ Passado } & \multicolumn{2}{|c|}{ Presente } & \multicolumn{2}{|c|}{ Futuro } \\
\hline & $\begin{array}{c}\text { Flexão } \\
\text { verbal } \\
\text { de } \\
\text { tempo }\end{array}$ & $\begin{array}{c}\text { Outros } \\
\text { marcadores }\end{array}$ & $\begin{array}{c}\text { Flexão } \\
\text { verbal de } \\
\text { tempo }\end{array}$ & $\begin{array}{c}\text { Outros } \\
\text { marcadores }\end{array}$ & $\begin{array}{c}\text { Flexão } \\
\text { verbal de } \\
\text { tempo }\end{array}$ & $\begin{array}{c}\text { Outros } \\
\text { marcadores }\end{array}$ \\
\hline 1 & 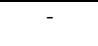 & - & - & - & - & - \\
\hline 2 & - & - & - & - & - & - \\
\hline 3 & - & - & - & - & - & - \\
\hline 4 & - & - & - & - & - & - \\
\hline 5 & - & - & - & - & - & - \\
\hline 6 & - & - & - & - & - & - \\
\hline 7 & - & - & $\begin{array}{c}\text { O Rodrigo } \\
\text { mesa limpa }\end{array}$ & - & - & - \\
\hline 8 & - & - & - & - & - & - \\
\hline 9 & - & - & - & - & - & - \\
\hline 10 & - & - & - & - & - & - \\
\hline 11 & - & $\begin{array}{c}\text { Antes comer } \\
\text { batata }\end{array}$ & - & $\begin{array}{c}\text { Hoje comer } \\
\text { banana }\end{array}$ & - & $\begin{array}{c}\text { Depois comer } \\
\text { uva }\end{array}$ \\
\hline 12 & - & - & - & - & - & -5 \\
\hline 13 & - & - & Ele corre rua & - & - & - \\
\hline 14 & - & - & $\begin{array}{c}\text { Homem joga } \\
\text { bola }\end{array}$ & - & - & - \\
\hline
\end{tabular}




\begin{tabular}{|c|c|c|c|c|c|c|}
\hline \multirow[b]{2}{*}{ Sujeitos } & \multicolumn{2}{|c|}{ Passado } & \multicolumn{2}{|c|}{ Presente } & \multicolumn{2}{|c|}{ Futuro } \\
\hline & $\begin{array}{c}\text { Flexão } \\
\text { verbal } \\
\text { de } \\
\text { tempo }\end{array}$ & $\begin{array}{c}\text { Outros } \\
\text { marcadores }\end{array}$ & $\begin{array}{c}\text { Flexão } \\
\text { verbal de } \\
\text { tempo }\end{array}$ & $\begin{array}{c}\text { Outros } \\
\text { marcadores }\end{array}$ & $\begin{array}{c}\text { Flexão } \\
\text { verbal de } \\
\text { tempo }\end{array}$ & $\begin{array}{c}\text { Outros } \\
\text { marcadores }\end{array}$ \\
\hline 15 & - & $\begin{array}{c}\text { Passado } \\
\text { menina limpar }\end{array}$ & - & $\begin{array}{l}\text { Hoje menina } \\
\text { limpar }\end{array}$ & - & $\begin{array}{c}\text { Futuro menina } \\
\text { limpar }\end{array}$ \\
\hline 16 & - & - & $\begin{array}{c}\text { Ele come } \\
\text { arroz }\end{array}$ & - & - & - \\
\hline 17 & - & $\begin{array}{c}\text { Eu pegar bola } \\
\text { passado }\end{array}$ & 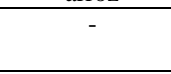 & $\begin{array}{c}\text { Eu pegar bola } \\
\text { hoje }\end{array}$ & - & $\begin{array}{l}\text { Eu pegar bola } \\
\quad \text { futuro }\end{array}$ \\
\hline 18 & $\begin{array}{l}\text { Ele pegou } \\
\text { papel }\end{array}$ & - & $\begin{array}{c}\text { Ele pega } \\
\text { papel }\end{array}$ & - & $\begin{array}{c}\text { Ele pegará } \\
\text { papel }\end{array}$ & - \\
\hline 19 & - & $\begin{array}{c}\text { Ele passado } \\
\text { pegar }\end{array}$ & - & Ele hoje pegar & - & $\begin{array}{c}\text { Ele futuro } \\
\text { pegar }\end{array}$ \\
\hline 20 & - & $\begin{array}{l}\text { Eu já corda } \\
\text { pular }\end{array}$ & - & Eu hoje pular & - & Eu depois pular \\
\hline 21 & $\begin{array}{c}\text { Eu joguei } \\
\text { de video } \\
\text { game }\end{array}$ & - & $\begin{array}{c}\text { Nós jogamos } \\
\text { de vídeo } \\
\text { game }\end{array}$ & - & $\begin{array}{c}\text { Nós } \\
\text { jogaremos de } \\
\text { vídeo game }\end{array}$ & - \\
\hline 22 & $\begin{array}{c}\text { O pai pegou } \\
\text { o jornal. }\end{array}$ & - & $\begin{array}{l}\text { O pai está } \\
\text { pega o R\$. }\end{array}$ & - & $\begin{array}{l}\text { A mãe pegará } \\
\mathrm{R} \$ \text { banco. }\end{array}$ & - \\
\hline Total & $\begin{array}{lr}\mathrm{N} & \% \\
3 & 13,6 \\
\end{array}$ & $\begin{array}{lc}\mathrm{N} & \% \\
5 & 22,7 \\
\end{array}$ & $\begin{array}{cc}\mathrm{N} & \% \\
7 & 31,8 \\
\end{array}$ & $\begin{array}{lr}\mathrm{N} & \% \\
5 & 22,7 \\
\end{array}$ & $\begin{array}{rr}\mathrm{N} & \% \\
3 & 13,6\end{array}$ & $\begin{array}{lr}\mathrm{N} & \% \\
5 & 22,7 \\
\end{array}$ \\
\hline
\end{tabular}

Legenda: - : A usência de flexão verbal ou recurso para marcação de tempo das frases, com o verbo escrito na forma nominal do infinitivo.

$\mathrm{N}$ : Número

Os sujeitos 18, 21 e 22 empregaram corretamente a flexão de tempo nos verbos apresentados, de acordo com o tempo solicitado para a realização das frases, usando o pretérito perfeito simples, presente e futuro do presente simples, do modo indicativo. Observa-se pela tabela 1 que estes sujeitos apresentam um tempo de escolaridade que varia de doze a catorze anos e estão matriculados em séries mais avançadas quando comparados com os demais surdos da pesquisa.

Os sujeitos 21 e 22 freqüentaram por um período maior a escola regular (7 e 10 anos respectivamente), já o sujeito 14 teve um tempo de permanência maior na escola especial (11 anos). Os dois sujeitos (Sujeito 21: 16 anos de idade e 7ạ série; Sujeito 22: 18 anos de idade e 7ạ série) que freqüentaram por um período maior a escola regular apresentaram um déficit menor em relação a idade e série escolar do que o sujeito que permaneceu um período maior na escola especial (Sujeito 18: 21 anos de idade e 6a série), demonstrando que o tempo de escolarização do surdo é influenciado pelo tipo de escola que freqüenta.

Os sujeitos 7, 13, 14 e 16 construíram as frases do tempo presente com os verbos flexionados na segunda pessoa do singular (Sujeito 13: Ele corre rua). Estes indivíduos utilizaram a mesma flexão verbal nos tempos passado e futuro. Este fato sugere que estes surdos ou estão em uma fase de aprendizado das flexões verbais de tempo, sendo que na escola é trabalhado com maior 
freqüência o tempo presente, havendo uma generalização desta flexão nos outros tempos, ou estes sujeitos não conseguem discriminar auditivamente o arquifonema / R/ desconsiderando-o. N este caso, estes indivíduos desconhecem que os tempos da frase devem ser marcados. A pesar desta hipótese, para a análise estatística desta pesquisa, as autoras consi deraram corretas as flexões verbais do tempo presente realizadas pelos sujeitos, com o objetivo de manter a fidedignidade dos dados coletados.

Quinze sujeitos não utilizaram as flexões verbais para marcar o tempo da frase e escreveram os verbos na forma nominal do infinitivo. Estes dados corroboram o estudo realizado por Fernandes (2003) com 40 surdos com escolaridademínima de quarta série do ensino fundamental, no qual foi observado o predomínio dos tempos presente, pretérito perfeito einfinitivo. Segundo a autora, apesar do verbo apresentar-se lexicalmente correto, os indivíduos não apresentaram domínio dos tempos e pessoas no processo de construção frasal.

Pode-se observar na tabela 3 que dos quinze sujeitos que não flexionaram o verbo, cinco utilizou-se de outros marcadores detempo para suprir a ausência da flexão verbal de tempo nas frases do passado, presente e futuro. Este fato demonstra que estes indivíduos, apesar de não conhecerem a flexão dos verbos da Língua Portuguesa, sabem marcar o tempo na frase para explicitar o momento da ação.

Para indicar que a ação ocorreu no passado, o sujeito 11, utilizou o advérbio "antes", os sujeitos 15, 17 e 19 utilizaram o vocábulo "passado" como adjunto adverbial e o sujeito 20 utilizou o advérbio "já". Para as frases no presente, os cinco sujeitos citados acima utilizaram o advérbio "hoje" e, para as frases no futuro, foi utilizado o vocábulo "futuro" como adjunto adverbial pelos sujeitos 15, 17 e 19, e o advérbio "depois" pelos sujeitos 11 e 20.

Estes marcadores de tempo utilizados nas frases escritas sugerem que estes sujeitos estejam transpondo a estrutura da Libras para a Língua Portuguesa, uma vez que, segundo Ferreira-Brito (1995) e Felipe (2005), na Libras o verbo não apresenta flexão de tempo, sendo comum o uso destes marcadores. Deste modo, a escrita de indivíduos surdos émarcada por al guns aspectos característicos da língua de sinais (FERREIRA; CÁRN IO, 1999; GÓES, 1999). É importante salientar que é comum o uso de traços da primeira língua quando se está adquirindo uma segunda língua (DEVITTO; BURGUESS, 2004), não sendo uma peculiaridade do surdo. De acordo com Svartholm (2008) até o momento não se conhece diferenças entre surdos e outros indivíduos que utilizam duas línguas diferentes para comunicação escrita e falada.

Dos dez sujeitos que não fizeram nenhuma marcação de tempo na frase, ou seja, não flexionaram o verbo e nem utilizaram outro marcador, cinco perguntaram à avaliadora porque era para escrever uma frase no passado, uma no presente e uma no futuro, pois podiam ser todas iguais. Como a avaliadora não deu nenhuma explicação no momento da avaliação, estes indivíduos 
escreveram a mesma frase nos três tempos solicitados. Este fato demonstra que estes sujeitos não conhecem a importância de se marcar o tempo em que a frase foi realizada na escrita, para que ocorra o bom entendimento do leitor sobre quando a ação foi, está ou irá ocorrer.

A troca na ordem das palavras (sujeito 20 "Eu já corda pular") e os elementos queficaram faltando (sujeito 13: "Elecorrerua") ou queforam acrescidos (sujeito 21: "Eu joguei de video game") inadequadamente nas frases dos surdos pode ser explicado pela falta de domínio da Língua Portuguesa pelos sujeitos.

A pesar dos surdos da pesquisa estarem adquirindo a Língua Portuguesa como segunda língua, esperava-se maior domínio desta, pelo tempo de escolaridade dos sujeitos. Deste modo, questiona-se as práticas de leitura e escrita em que estes surdos foram expostos.

De acordo com a literatura, a pouca experiência educacional e muitas vezes empobrecida transmitidas pelo professor aos estudantes surdos prejudica o desenvolvimento da linguagem escrita destes indivíduos (GÓES, 1999; BOTELHO, 2002; GÓES; TARTUCI, 2002).

Lodi (2006) relata a necessidade dos espaços educacionais serem compostos por práticas que considerem a linguagem escrita em sua dinâmica discursiva, sendo a Libras a língua de instrução que irá proporcionar o aprendizado dos conteúdos.

Durante a avaliação pôde ser observado a preocupação dos surdos em não cometerem erros, o que pode ter contribuído para que todos os sujeitos escrevessem frases simples.

A estrutura frasal dos dez sujeitos que utilizaram o verbo na forma nominal do infinitivo e que não utilizaram nenhum marcador de tempo na frase foi composta pelas seguintes classes gramaticais: sujeito, verbo e objeto (organizados estruturalmente deformas variadas), em todos os tempos solicitados.

Os dados da pesquisa vão de encontro a literatura, no qual se observa que os estudantes surdos são estimulad os a reproduzir model os frasais forneci dos pelos professores, resultando na produção de frases que atendem aos requisitos morfossintáticos da Língua Portuguesa, mas sem criatividade e muitas vezes sem sentido (MIDENA,1989; FERREIRA; CÁRNIO, 1999; GÓES, 1999; SÃO PAULO, 2005).

$\mathrm{Na}$ tabela 4 estão expostos os resultados das correlações entre as flexões verbais de tempo das frases do passado, presente e futuro com as séries escolares dos sujeitos. Para esta análise estatística foi utilizado o teste Qui-Quadrado para Independência. 
Tabela 4 - Comparação das flexões verbais de tempo com a série escolar.

\begin{tabular}{c|c|c|c|c|c|c|c|c}
\hline \multicolumn{2}{c|}{\begin{tabular}{c} 
Flexão verbal de \\
\multicolumn{2}{c|}{ tempo }
\end{tabular}} & \multicolumn{2}{c|}{ Não } & \multicolumn{2}{c|}{ Sim } & \multicolumn{2}{c}{ Total } & \multirow{2}{*}{ p-valor } \\
\hline \multirow{4}{*}{ Passado } & $3^{\mathrm{a}}$ e $4^{\mathrm{a}}$ & 10 & $52,6 \%$ & 0 & $0,0 \%$ & 10 & $45,5 \%$ & \\
& $5^{\mathrm{a}}$ a $7^{\mathrm{a}}$ & 9 & $47,4 \%$ & 3 & $100 \%$ & 12 & $54,5 \%$ & $0,089 \#$ \\
& Total & 19 & $86,4 \%$ & 3 & $13,6 \%$ & 22 & $100 \%$ & \\
\hline \multirow{4}{*}{ Presente } & $3^{\mathrm{a}}$ e $4^{\mathrm{a}}$ & 9 & $60,0 \%$ & 1 & $14,3 \%$ & 10 & $45,5 \%$ & \\
& $5^{\mathrm{a}}$ a $7^{\mathrm{a}}$ & 6 & $40,0 \%$ & 6 & $85,7 \%$ & 12 & $54,5 \%$ & \multirow{2}{*}{$0,045^{*}$} \\
& Total & 15 & $68,2 \%$ & 7 & $31,8 \%$ & 22 & $100 \%$ & \\
\hline \multirow{4}{*}{ Futuro } & $3^{\mathrm{a}}$ e $4^{\mathrm{a}}$ & 10 & $52,6 \%$ & 0 & $0,0 \%$ & 10 & $45,5 \%$ & \\
& $5^{\mathrm{a}}$ a $7^{\mathrm{a}}$ & 9 & $47,4 \%$ & 3 & $100 \%$ & 12 & $54,5 \%$ & $0,089 \#$ \\
& Total & 19 & $86,4 \%$ & 3 & $13,6 \%$ & 22 & $100 \%$ & \\
\hline
\end{tabular}

Legenda: Qtde: Quantidade

*: p-valores considerados estatisticamente significantes

\# :p-valores que tendem a ser significativos

Observa-se que houve relação estatisticamente significante entre a flexão verbal do tempo presentecom o aumento da escolaridade. As flexões verbais do passado e do futuro apresentaram tendência à significância em relação ao avanço das séries escolares.

O fato de apenas a flexão verbal do presente ter sido estatisticamente significante com o aumento da escolaridade se deve a produção escrita de quatro sujeitos da pesquisa, que utilizaram esta flexão verbal na segunda pessoa do singular também nos tempos passado efuturo. Desdemodo, considerou-secorreta a flexão verbal do presente para respeitar-se a autenticidade dos dados coletados, pois acredita-se que ou estes sujeitos estão realizando uma generalização, ou desconhecem que os tempos das frases devem ser marcados.

A pesar da dificuldade dos sujeitos da pesquisa na real ização da flexão verbal de tempo na construção das frases, observa-se que com o aumento da escolaridadeo uso desta flexão verbal torna-semais freqüente. Estedado corrobora o estudo de Gonçalo (2004) no qual a inconsistência do tempo verbal não apareceu na escrita de surdos em fase de final ização do Ensino Médio, sugerindo que este tipo de dificuldade parece ser superado com o avanço da escolaridade.

De fato, com o aumento do grau de escolaridade os sujeitos vão sendo expostos a um maior número de gêneros textuais que amplia o conhecimento de mundo e favorece a aquisição dos el ementos gramaticais da Língua Portuguesa escrita. 
A aquisição da Língua Portuguesa escrita, como segunda língua para os surdos, poderia ser adquirida de forma mais natural e significativa se os professores que trabal hassem com estes sujeitos fossem fluentes na Língua Brasileira deSinais. Isto possibilitaria ao professor transmitir os conteúdos de forma que as similaridades e as diferenças entre a língua escrita e a língua de sinais fossem destacadas. O surdo teria a oportunidade de desenvolver gradativamente o conhecimento sobre a estrutura da língua escrita, sendo que as dificuldades inerentes ao seu aprendizado poderiam ser previstas e tratadas de forma adequada (SVARTHOLM, 2008).

$\mathrm{Na}$ tabela 5 estão expostos os resultados das correlações entre os marcadores de tempo utilizados pelos sujeitos para suprir a ausência da flexão de tempo do verbo e marcar o tempo das frases do passado, presente e futuro com as séries escolares dos sujeitos. Para esta análise estatística também foi utilizado o teste Qui-Quadrado para Independência.

Tabela 5 - Comparação dos marcadores de tempo (com exceção da flexão verbal) das frases com a série escolar.

\begin{tabular}{|c|c|c|c|c|c|c|c|c|}
\hline \multirow{2}{*}{\multicolumn{2}{|c|}{$\begin{array}{l}\text { Marcadores de } \\
\text { tempo }\end{array}$}} & \multicolumn{2}{|c|}{ Não } & \multicolumn{2}{|c|}{ Sim } & \multicolumn{2}{|c|}{ Total } & \multirow{2}{*}{$\mathrm{p}$-valor } \\
\hline & & Qtde & $\%$ & Qtd & $\%$ & Qtde & $\%$ & \\
\hline \multirow{3}{*}{ Passado } & $3^{\mathrm{a}}$ e $4^{\mathrm{a}}$ & 10 & $58,8 \%$ & 0 & $0,0 \%$ & 10 & $45,5 \%$ & \multirow{3}{*}{$0,020 *$} \\
\hline & $5^{\mathrm{a}}$ a $7^{\mathrm{a}}$ & 7 & $41,2 \%$ & 5 & $100 \%$ & 12 & $54,5 \%$ & \\
\hline & Total & 17 & $77,3 \%$ & 5 & $22,7 \%$ & 22 & $100 \%$ & \\
\hline \multirow{3}{*}{ Presente } & $3^{\mathrm{a}}$ e $4^{\mathrm{a}}$ & 10 & $58,8 \%$ & 0 & $0,0 \%$ & 10 & $45,5 \%$ & \multirow{3}{*}{$0,020 *$} \\
\hline & $5^{\mathrm{a}} \mathrm{a} 7^{\mathrm{a}}$ & 7 & $41,2 \%$ & 5 & $100 \%$ & 12 & $54,5 \%$ & \\
\hline & Total & 17 & $77,3 \%$ & 5 & $22,7 \%$ & 22 & $100 \%$ & \\
\hline \multirow{3}{*}{ Futuro } & $3^{a}$ e $4^{a}$ & 10 & $58,8 \%$ & 0 & $0,0 \%$ & 10 & $45,5 \%$ & \multirow{3}{*}{$0,020 *$} \\
\hline & $5^{\mathrm{a}}$ a $7^{\mathrm{a}}$ & 7 & $41,2 \%$ & 5 & $100 \%$ & 12 & $54,5 \%$ & \\
\hline & Total & 17 & $77,3 \%$ & 5 & $22,7 \%$ & 22 & $100 \%$ & \\
\hline
\end{tabular}

Legenda: Qtde: Quantidade

*: p-valores considerados estatisticamente significantes

De acordo com os dados, pode-se observar que houve relação estatisticamente significante dos marcadores de tempo das frases com o aumento da escolaridade dos sujeitos, demonstrando que estes surdos apesar de não saberem flexionar o verbo de acordo com o tempo, têm conhecimento da necessidade de marcar as frases para que fique claro quando a ação foi realizada.

Gonçalo (2004) encontrou em seu estudo indícios de que os surdos usam estratégias que buscam adequar a escrita de acordo com as normas da 
gramática da Língua Portuguesa, mesmo quando produzem textos próximos da estrutura da língua de sinais.

\section{ConcLusões}

A pesar do tamanho reduzido da amostra, e, portanto, da impossibilidade de generalização, os dados demonstraram que os surdos desta pesquisa que se encontram na terceira e quarta série do Ensino Fundamental (com exceção de um) desconhecem que na escrita do português as frases devem ser marcadas de acordo com o tempo em que ocorreu a ação. Os surdos da pesquisa que cursam séries mais avançadas (quinta, sexta e sétima série) apresentaram melhor desempenho no uso das flexões verbais de tempo ou utilizaram outros marcadores de tempo na escrita de frases do português.

O uso de marcadores de tempo da Libras na escrita das frases do Português sugerem uma evolução na produção escrita dos sujeitos, uma vez que possibilitou ao leitor uma compreensão do tempo em que a ação foi realizada, apesar da ausência da flexão verbal de tempo.

É imprescindível que os profissionais que trabalham com a escrita de surdos sinalizadores sejam fluentes em Libras e conheçam a gramática desta língua, para o desenvolvimento de um trabal ho de conscientização das diferenças das estruturas da Língua Portuguesa escrita e de sinais. A produção escrita deve ser trabal hada de forma prazerosa e significativa para que os surdos percebam a importância do conhecimento da Língua Portuguesa para sua inclusão na sociedade letrada.

\section{RefERÊNCIAS}

BOTELHO, P. Linguagem el etramento na educação dos surdos: ideologias e prática pedagógicas. Belo Horizonte: Autêntica, 2002.

BRASIL. M inistério da Educação e Cultura Parâmetros Curriculares N acionais - adaptações curriculares, estratégias para a educação de al unos com necessidades educacionais especiais. Brasília, 1999.

CA PORALI, S. A. LACERDA, C.B.; MARQUES, P.L. Ensino delíngua desinais a familiares de surdos: enfocando a aprendizagem. Pró-Fono Revista de A tualização Científica, Barueri, v.17, n.1, p.89-98, 2005.

CÁRNIO, M. S. Leitura e desenvolvimento da estrutura frasal em nível de escrita em deficiência auditiva: estudos com a técnica de cloze. 1986. 248f. Dissertação (M estrado) Faculdade de Educação, Pontifícia Universidade Católica de São Paulo, São Paulo. 
CÁ RNIO, M. S. Conceitos ecompreensão da leitura do su rdo no contexto da edu cação especial . 1995. 181f. Tese (Doutorado) - Faculdade de Filosofia Letras e Ciências Humanas, Universidade de São Paulo, São Paulo, 1995.

CÁRNIO, M.S. et al. Disponibilidadepara atividades deleitura eescrita decrianças surdas e ouvintes de três a cinco anos de idade. Pró-F ono R evista de A tualização Científica, Barueri, v.12, n.2, p.67-72, 2000.

CEGA LLA, D. P. Morfologia: verbos. In: . N ovíssima gramática da língua portuguesa. 44.ed. São Paulo: Companhia Editora Nacional, 2001. p.182-242.

DEVITTO Z, BURGESS C. Theorical and methodological implications of language experience and vocabulary skill: priming of strongly and weakly associated words. Brain Cogn, v.55,n.1, p. 295-99, 2004.

FELIPE, T. A. Libras em contexto: curso básico. 5.ed. Rio de Janeiro: Libregraf, 2005.

FERNANDES, E. Problemas lingüísticos e cognitivos do surdo. Rio de Janeiro: Agir, 1990.

. Uma análise do instrumental lingüístico em língua portuguesa em surdos adultos. In: . Linguagem e surdez. Porto A legre: A rtmed, 2003. p. 61-147.

FERREIRA-BRITO, L. Morfofonologia esintaxeda Libras. In: Por uma gramática delínguas de sinais. Rio de Janeiro:Tempo Brasileiro, 1995. p. 35-67.

FERREIRA,S.; CÁRNIO, M.S. Interferências do A cesso às Distintas Modalidades Lingüísticas no Processo de Escrita Espontânea do Surdo Inserido no Contexto de Educação Especial. Pró-Fono Revista de A tualização Científica, Barueri, v.11, n.2, p.38-45, 1999.

GESUELI, Z.M. Língua(gem) eidentidade: a surdez em questão. E duc. Soc., Campinas, v. 27, n.94, p.277-292, 2006.

GÓES, M.C.R. O surdo na escola: a escrita, a fala e os sinais. In: . Linguagem, surdez e educação. 2.ed. Campinas: Autores Associados, 1999. p. 1-24

GÓES, M.C.R.; TARTUCI, D. Alunos surdos na escola regular: as experiências deletramento eos rituais da sala deaula. In: LODI , A.C.B. etal . (Org.). L etramento e minorias. Porto Alegre: Mediação, 2002.p.110-119.

GON ÇALO, S.F. Perfil da produção escrita e da traj etória escolar dealunos surdos deEnsino M édio. 2004. 245f. Dissertação (Mestrado) - Faculdade de Educação, Universidade de São Paulo, São Paulo, 2004.

KARN OPP, L.B. Língua de sinais e língua portuguesa: em busca de um diálogo. In: LODI, A.C.B. et al. (Org.). L etramento eminorias. Porto Alegre: Mediação, 2002.p.56-61.

KARNOPP, L.B.; PEREIRA, M.C.C. Concepções deleitura edeescrita eeducação desurdos. In: LODI, A.C.B; HARRISON , K.M.P;CAMPOS,S.R.L (Org.). Leitura e escrita: no contexto da diversidade. Porto Alegre: Mediação, 2004. p.33-38.

KYLE, J. Deaf children learning to sign. Rev. O nlineda Bibl. Prof. J oel M artins, Campinas, v.2, n.3, p. 27-37, 2001a.

. A pessoa surda: aspectos de desenvolvimento / aprendizagem econtextos de educação bilíngüe. Rev. O nline da Bibl. Prof. Joel M artins, Campinas, v.2, n.3, p. 117-128, $2001 b$. 
LACERDA, C.B.F. O intérprete delíngua desinais no contexto deuma sala deaula dealunos ouvintes: problematizando a questão. In: LACERDA, C.B.F.; GÓES, M.C.R. (Org.). Surdez: processos edu cativos e subj etividade. São Paulo: Lovise, 2000. p.51-84.

. A inclusão escolar de alunos surdos: o que dizem al unos, professores eintérpretes sobre esta experiência. Caderno do CED ES, Campinas, v.26, n.69, p.205-229, 2006.

LODI, A.C.B; HARRISON, K.M .P; CAM POS,S.R.L . Letramento esurdez: um olhar sobreas particularidades dentro do contexto educacional. In: LODI, A.C.B. et al . (Org.). L etramento e minorias. Porto A legre: Mediação, 2002.p.35-46.

LODI ACB, A leitura como espaço discursivo de construção de sentidos: oficinas com surdos. 2004. 282 f. Tese(doutorado) - Pontifícia Universidade Católica São Paulo, São Paulo, 2004.

. A leitura em segunda língua: práticas de linguagem constitutivas da(s) subjetividade(s) de um grupo de surdos adultos. Caderno do Cedes, Campinas, vol. 26, n. 69, p. 185-204, 2006.

MIDENA, M.C.M. M emórias da educação e do trabalho de surdos. 1989. 129f. Dissertação (Mestrado) - Faculdade deEducação, Pontifícia UniversidadeCatólica, São Paulo, 1989.

PEIXOTO, R.C. Al gumas considerações sobrea interface entrea Língua Brasileira deSinais (LIBRAS) ea língua portuguesa na construção inicial da escrita pela criança surda. Caderno do CEDES, Campinas, v.26, n.69, p.205-229, 2006.

PEREIRA, M.C.C. Papel da língua de sinais na aquisição da escrita por estudantes surdos. In: LODI, A.C.B. et al. (Org.). Letramento eminorias. Porto Alegre: Mediação, 2002. p.47-55.

PICKERGILL, M.; GREGORY, S. Sign Bilingualism. London: Laser, 1998.

QUADROS, R.M. Educação de surdos: aquisição da linguagem. São Paulo: Artes Médicas, 1997.

QUINTANO-NEIRA, P R N.; CÁ RNIO, M S. Caderno llustrado deV erbos: um recurso pedagógico para o desenvolvimento da Língua portuguesa. Barueri: Pró-Fono, 2005.

RATHMAN N, C.; MAN N, W.; MORGAN, G. Narrativestructureand narrativedevelopment in deaf children. D eafness and Education International, v.9, n.4, p. 187-196, 2007.

SA LLES, H. M. M. L. et al. Tempo easpectos verbais. In: . Ensino delíngua portuguesa para surdos: caminhos para a prática pedagógica.Brasília: MEC / SSESP, 2004. p.182-201.

SAMELLI, A.G. et al. Perfil das classes especiais freqüentadas por surdos atendidos no Setor deAudiologia Educacional daFMUSP. Temas sobreD esenvolvimento, v.11, n.61, p.16-24, 2002.

SÃ O PAULO. Secretaria da Educação. Leitura, escrita esurdez. PEREIRA, M. C. C. (Org.). São Paulo: FDE, 2005.

SOUZA, R.M. Q ue palavra que te falta? : lingüística, educação e surdez. São Paulo: Martins Fontes, 1998.

STRONG, M.; PRINZ, P.M. A study of the relationship between A merican Sign Language and English literacy. Journal of D eaf Studies and D eaf E ducation,v.2, n.1, p.37-46, 1997. 
SVARTH OLM , K. Educação bilíngüe para os surdos na Suécia: Teoria eprática. In: MOURA, M.C; VERGAMINI, S.A.A; CAM POS, S.R.L. (Org.). Educação paraSurdos: Práticase Perspectivas. São Paulo: Santos Editora, 2008. p.119-144.

UNESCO. D eclaração de Salamanca: linha de ação sobre necessidades educativas especiais. Salamanca, Espanha, 1994.

WILLIAMS, C.L. Preschool deaf children's use of signed language during writing events. Journal of Literacy R esearch, v.31, n.2, p.183-212, 1999. 